\title{
The food environment, its effects on dietary consumption, and potential for measurement within agriculture-nutrition interventions
}

\author{
Anna Herforth $^{1} \cdot$ Selena Ahmed ${ }^{2}$
}

Received: 21 January 2015 / Accepted: 25 March 2015 / Published online: 7 May 2015

(C) The Author(s) 2015. This article is published with open access at Springerlink.com

\begin{abstract}
The food environment in markets constrains and signals consumers what to purchase. It encompasses availability, affordability, convenience, and desirability of various foods. The effect of income on dietary consumption is always modified by the food environment. Many agricultural interventions aim to improve incomes, increase food availability and reduce food prices. Their effects on nutrition could be better understood if food environment measures helped to explain how additional income is likely to be spent, and how food availability and prices change as a result of large-scale interventions. Additionally, measurement of the food environment could elucidate food access gaps and inform the design of nutrition-sensitive interventions. This paper reviews existing measures of the food environment, and then draws from these tools to suggest ways the food environment could be measured in future studies and monitoring.
\end{abstract}

Keywords Food environment · Agriculture-nutrition · Food access $\cdot$ Dietary consumption $\cdot$ Monitoring

Special section series Strengthening the links between nutrition and health outcomes and agricultural research

Anna Herforth

anna@annaherforth.net

1 SPRING, 1616 Fort Myer Drive 16th Floor, Arlington, VA 22209, USA

2 Department of Health and Human Development, Montana State University, Bozeman, MT 59717, USA

\section{Introduction}

Agricultural investments often have the primary goals of increasing productivity and income. Similarly, in the case of agriculture interventions aimed at improving nutrition, many rely upon income as a pathway to nutrition, or on increasing production that leads to greater food availability (World Bank 2007a). For example, in an analysis of Feed the Future activities, $100 \%$ of USAID missions relied on the income-food purchase pathway to improve nutrition, as well as the production-own consumption pathway (Du 2014).

Much of agriculture-nutrition advocacy, however, cautions against over-reliance on income generation as a means to improve nutrition (FAO 2013a). Previous evaluations of agricultural interventions have shown that income may rise without improvements in nutritional status (von Braun and Kennedy 1994; World Bank 2007a). There are several reasons why nutrition may not improve with increased income. One has to do with who is controlling the income, because there are well-documented differences in how women and men tend to use income in many contexts (Smith et al. 2003; UNICEF 2011). Another reason is that, in many contexts, the strongest causes of child malnutrition have to do with caring practices that are not clearly linked to income. Yet another plausible reason is that food environments do not support and encourage the use of income on healthy diets. Expectations for a positive effect of income on nutrition may need to be tempered with an understanding of what foods consumers are likely to purchase as their income rises.

\section{Does increased income lead to improved diets?}

Overall, does diet quality improve with income? It depends on how diet quality is measured, and which aspects of diet 
quality are examined. "Dietary quality" has been described as having at least two basic components: adequacy of healthpromoting foods, food groups and nutrients; and moderation of foods, food groups and nutrients linked with poor health outcomes (Guenther et al. 2008). Agricultural GDP growth is associated with faster reductions in undernutrition, and also faster increases in overweight and obesity than nonagricultural GDP growth (Webb and Block 2012). Mainly this is because agricultural GDP reaches the poor more effectively (World Bank 2007b). This pattern of change in nutritional status suggests that income increases are associated with improvements in adequacy of diets but declines in moderation. An example of this is Brazil: it is internationally heralded for bringing down malnutrition rates from 13.5 to $6.8 \%$ in 10 years through multiple routes including maternal schooling, increased income, and improved primary health care and sanitation (Monteiro 2009). At the same time, diets are increasingly high in ultra-processed foods, associated with a variety of indicators of poorer diet quality including lower intakes of fiber and protein, higher saturated fat, free sugars, sodium, and energy density (Monteiro et al. 2011). The outcome is a nutrition transition: lower undernutrition, and higher overweight and chronic disease in Brazil, with the most rapid increases in overweight among the poorest groups (Monteiro et al. 2007).

As income levels rise, demand for food variety rises quickly (Behrman and Deolalikar 1989). The portion of an additional dollar of food spending on staple cereals decreases quickly; also the portion spent on fruits and vegetables tends to decline quickly, while spending on "other" foods (such as prepared/ convenience foods) and beverages increases (Muhammad et al. 2011). Similarly, as national income rises, the proportion of calories from starches and plant-source proteins declines, and the proportion of calories from animal fats and proteins and from sweeteners increases (Drewnowski and Popkin 1997). These data on average dietary changes at population level are cross-sectional, however, and do not reflect variation in trajectories by country. As income rises, changes in diets and nutrition have been somewhat predictable, known as the nutrition transition (Popkin et al. 2012), but there is variation across countries (Keats and Wiggins 2014). For example, South Korea has experienced much lower rates of obesity and non-communicable disease than would be expected based on its income growth, which has been explained by maintenance of nutritious traditional diets (Lee 2002). Conversely, rates of obesity and diabetes in Mexico are higher than expected based on GDP alone, higher than in the United States (FAO 2013b; IDF 2013), and it has one of the highest rates of sugar-sweetened beverage consumption in the world (Barquera et al. 2008).

Other evidence demonstrates that the relationship between income and diet quality varies by context. For example, while there is a consistent positive correlation between income and dietary diversity across contexts, the magnitude is variable. Hoddinott and Yohannes (2002) show that the elasticities of association between dietary variety (number of unique foods consumed at the household level) and expenditures (a measure of income) range from 0.39 to 1.37; meaning that in some settings (such as India in the post-harvest season), a $1 \%$ increase in dietary variety is associated with a very small increase in income $(0.39 \%)$, while in other settings (such as Mexico), the same increase in dietary variety is associated with a larger increase in income $(1.37 \%)$. In other words, the same increase in income is associated with greater increase in dietary variety in India than in Mexico. Some of this variation may have to do with the availability of foods, as well as the extent to which people depend on markets (as opposed to own-production) for their diets.

Standard economic tools exist to describe the relationship between income and consumption: Engel curves can be drawn for each kind of food to depict how expenditures vary with income, indicating that certain foods have higher or lower status. Income elasticities of demand show how likely people are to consume certain products if their income increases. However, neither Engel functions nor income elasticities of demand are static. Drewnowski and Popkin (1997) showed that the income-diet relationship first described in the 1960s changed significantly by the 1990 s, particularly in that fat consumption is less well predicted by GNP. A study of the nutrition transition in China shows that the income elasticities of demand shifted rapidly, so that in 1997, an increase in income among the poor led to a greater increase in meat than it had just 8 years earlier (Popkin and Du 2003). This reflects changes in the food environment wherein meat was more available and cheaper.

\section{Defining the food environment}

We define the food environment as the availability, affordability, convenience, and desirability of various foods. This is similar to other definitions, ${ }^{1}$ but with some important distinctions: First, we consider policy and sociocultural aspects to affect the food environment, but limit the scope of our definition to the above characteristics of actual foods. Second, our definition includes convenience, unlike other definitions. Third, it uses the broader term "desirability" which encompasses but is more than "quality" which is used in other

\footnotetext{
${ }^{1}$ Food environments are defined as the collective physical, economic, policy and socio-cultural surroundings, opportunities and conditions that influence people's food and beverage choices and nutritional status and they include things as such as food composition, food labelling, food promotion, food prices, food provision in schools and other settings, food availability and trade policies affecting food availability, price and quality. (Swinburn et al. 2014)
} 
definitions (Swinburn et al. 2014; Health Canada 2013). The on-farm and natural/wild food environments are part of the food environment for producers and rural residents (see Powell et al. 2015), but this paper focuses on the food environment in markets, for the purpose of strengthening evaluation of agriculture interventions that seek to improve nutrition through higher income or lower food prices.

The food environment always modifies the effect of income on dietary consumption. The interaction of income and the food environment explains why household income has a variable - and sometimes seemingly unpredictable or less than expected - impact on nutrition. This interaction can have a strong positive influence where the food environment enables its use on healthy diets. Increased income may worsen nutrition in some ways when food environments facilitate spending toward unhealthy diets. The food environment in markets is important for nutrition because it constrains and signals consumers what to purchase. It affects diets by circumscribing how income can possibly be spent on food (what kind of food is available), as well as how income is likely to be spent (based on affordability, convenience, and desirability of various foods).

An ecological approach recognizes the complex factors and contexts that influence individual dietary patterns. The USDA Dietary Guidelines for Americans, and other publications, use an ecological model to illustrate how individual, environmental, and social factors explain differences in dietary behaviors (USDA and DHHS 2010; Story et al. 2008; Dufour et al. 2012; Glanz et al. 2005; Lytle 2009). The social ecological model used by the USDA (Fig. 1) places individual factors such as knowledge and taste within environmental settings (the food environment). Sectors including agriculture, marketing, industry, and government influence the food environment, and are set within social and cultural norms and values. Domestic nutrition research in high-income countries uses the ecological approach to diet and health outcomes routinely, and describes the role the food environment plays in food choices and nutrition transitions (Popkin et al. 2005; Larson and Story 2009; Swinburn et al. 2011; Wansink 2010; Drewnowski et al. 2013; Brownell et al. 2010). In international nutrition research and advocacy, the food environment has been considered to a lesser extent.

\section{How the food environment affects consumption}

\section{Availability}

Broadly, what is available is what is consumed. In the U.S., an analysis of the food supply shows, unsurprisingly, that it matches closely with actual average diets, but not with dietary recommendations (Reedy et al. 2010). It is difficult to determine the causal direction between associations of food availability and consumption, as the relationship is bi-directional. However, at a very basic level availability must precede consumption; a food cannot be consumed if it is not available at all.

Availability of different kinds of food has shifted profoundly in the last 20-50 years. Khoury et al. 2014 show that over the past 50 years, species grown across countries have become more similar. Globally, more calories, protein, and fat are produced from fewer species and with increased proportions of quantities coming from energy-dense foods. From 1961 to 2009, "homogeneity increased by $16.7 \%$, as measured by the mean change in similarity between each country and the global standard composition, with a maximum (singlecountry) change of $59.7 \%$ " (Khoury et al. 2014, p.4002). The largest shifts toward the global standard occurred in sub-Saharan Africa and East and Southeast Asia. The authors note that the increasing similarity of production reflects
Fig. 1 Social ecological framework for nutrition and physical activity decisions (Source: Reproduced from the USDA Dietary Guidelines for Americans 2010)

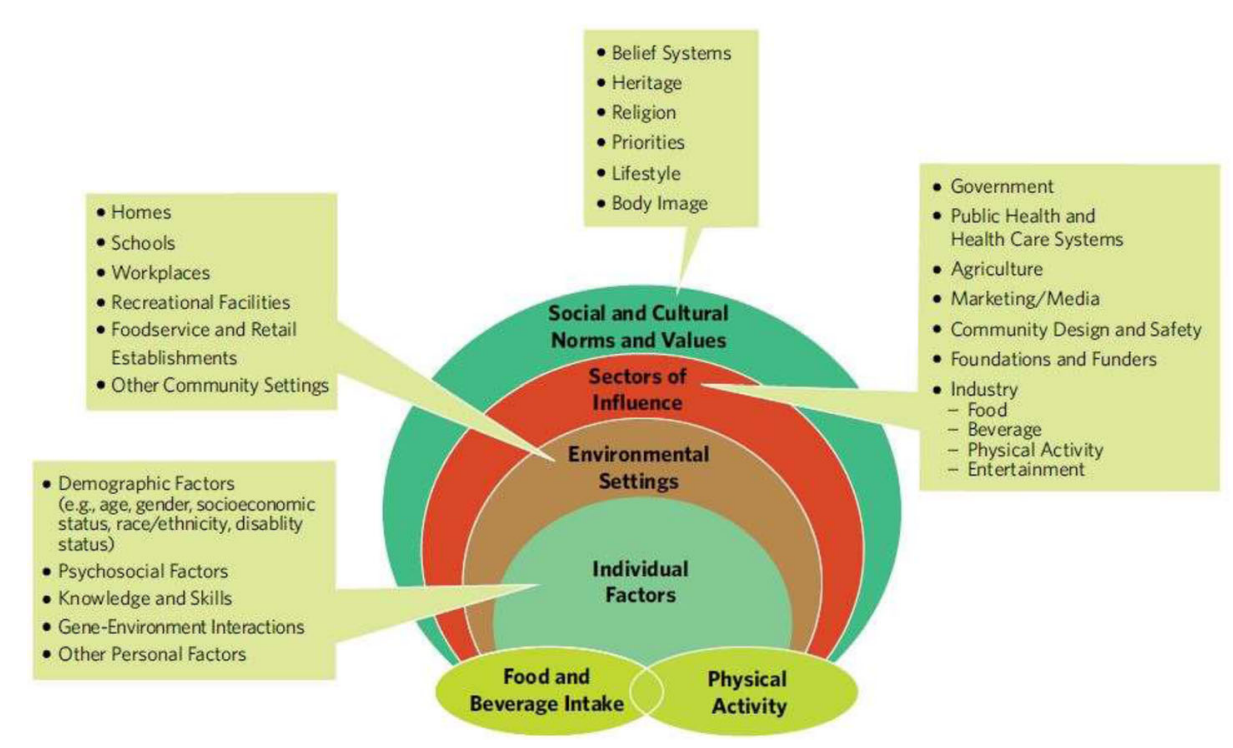


interdependence among countries regarding the availability and exchange of foods, and a global homogenization of diets.

Based on current food availability it is theoretically possible for all people to consume enough calories, but it is not possible for all to consume nutritious diets. Fruit and vegetable availability cannot meet population needs to achieve dietary recommendations in most countries (Siegel et al. 2014; Keats and Wiggins 2014). Pulse availability has declined globally as a proportion of calories (Khoury et al. 2014), with a decrease of almost one third from 1961 to 2009 including in East and South Asia (Keats and Wiggins 2014) where pulses are a nutritionally and culturally important part of traditional diets (Graham et al. 2007; Bouis et al. 2011). In Africa, the availability of pulses is about one third of estimated needs (Herforth 2015). Conversely, staple cereal and oil availability has gone up worldwide and in all regions; the commodities with the greatest spread from 1961 to 2009 were oil crops, including soybean, sunflower, and palm oil (Khoury et al. 2014). Supply of animal-source foods rose $40 \%$ from 1961 to 2009 , with major increases in poultry, pork, and beef; consumption of these foods rose $82 \%$ in the same period globally (Keats and Wiggins 2014).

These trends have led some to conclude that future food production must primarily increase cereal, meat, and oil crop production - because those have increased fastest in supply and consumption to date. A USAID infographic states that "cereal production must rise by $42 \%$ ", and "beef production must rise by over $100 \%$ by 2050 to meet our needs" (USAID 2014). The CGIAR "Big Facts: Food Security" website cites research stating that cereal production, meat production, and oil crop production "must increase" by 940, 196, and 133 million tonnes, respectively, to meet global food demand in 2050 (CGIAR 2014; Alexandratos and Bruinsma 2012). These estimates include the commodity crops and livestock that have traditionally been a focus of agricultural research and investment. ${ }^{2}$ Other food groups are not mentioned in these declarations of need for food in the coming decades.

Fast foods and ultra-processed foods ${ }^{3}$ sold by transnational food companies have also increased dramatically in availability throughout the developing world (Pingali 2006; Monteiro et al. 2010). Yet it would not be said that since demand is high for fast food, more fast food should be made available as a matter of public policy. Inasmuch as policy is promoting cereal, meat, and oil crop production, a side effect is that it may

\footnotetext{
${ }^{2}$ The investment in basic agricultural research on legumes and vegetables is $5 \%$ and $1 \%$, respectively, compared to the overall CGIAR budget (World Bank 2014).

3 "Ultra-processed products are made from processed substances extracted or refined from whole foods - e.g., oils, hydrogenated oils and fats, flours and starches, variants of sugar, and cheap parts or remnants of animal foods - with little or no whole foods. . . [They] are typically energy dense; have a high glycaemic load; are low in dietary fibre, micronutrients, and phytochemicals; and are high in unhealthy types of dietary fat, free sugars, and sodium." (Moodie et al. 2013)
}

be supporting the processed food industry and the availability of ultra-processed foods. "In high-income and rapidly growing low-income countries, the agricultural sector has become or is rapidly becoming a supplier of raw materials for the food processing industry, rather than a provider of food for direct consumption" (Pinstrup-Andersen 2013, p.9). The vast majority of palm oil, for example, is used in ultra-processed foods and other items, rather than consumed whole. A large proportion of commercially-produced cereals and soybean are used for livestock production.

An alternative viewpoint to maintaining the status quo and focusing investments on cereal, oil, and meat production, is that there is a need to shift diets to sustainably nourish the planet (Foley 2014). This may be a necessity not just for sustainability, but also for public health. The Global Burden of Disease project shows that dietary risks are the top cause of years of life lost in all developing countries combined (IHME 2013). The top contributors to dietary risks include low fruits and vegetables, high sodium, low nuts and seeds, low whole grains, low omega-3 fatty acids, low fiber, and high processed meat (IHME 2013) - exactly what would be expected based on the food supply. Lack of availability is the most basic level of the food environment that affects dietary choices. Further, availability of food is related to prices.

\section{Affordability}

Overall, how much do healthy diets cost? A growing literature consistently shows that the cost of a healthy diet is higher than the cost of an unhealthy diet. A systematic review of cost-ofdiet studies globally found that healthy diets were, on average, approximately $\$ 10.50$ /week more expensive than less-healthy diets, and that this difference was similar across countries adjusting for purchasing power parity (Rao et al. 2013). ${ }^{4}$ In the UK, a recent study disaggregated diets into five categories of "healthfulness" and found that the healthiest diet was double the price of the least healthy diet (Morris et al. 2014). In the US, there is an inverse relationship between energy density and energy cost, and refined grains, added sugars, and fats are much more affordable than the diet recommended by dietary guidelines (Drewnowski and Darmon 2005a; b). While most research on this question is from high-income countries, Chastre et al. (2009) found that healthy diets were unaffordable for large portions of the population in all sites studied (Ethiopia, Myanmar, Tanzania, and Bangladesh), costing between $\$ 0.72$ and $\$ 1.27 /$ day at a minimum. In South Africa, Temple and Steyn (2011) found that a healthier diet costs $69 \%$ more than an unhealthy diet on average, and that if healthy foods were carefully selected economically, a healthy diet would add

\footnotetext{
${ }^{4}$ All the studies available were from high-income countries, except for Brazil and South Africa.
} 
costs of $10-15 \%$ of total household income on average for most families (all those except the wealthiest one-third).

If healthy diets are expensive, then the policy-relevant question is, what is the best way to lower the cost of a healthy diet? One hypothesis is that because staple grains take up the majority of food intakes and expenditures of the poor, if staple prices decline, it will drive down food prices overall and more income will be freed to purchase micronutrient-rich foods, and dietary quality will improve. A second hypothesis is that lower prices of micronutrient-rich foods will lead to greater consumption of them, and dietary quality will improve. Using existing literature on consumption and elasticities, we examine these hypotheses.

When staple prices rise, diet quality among the poor tends to decline. Bouis et al. (2011) show that when staple prices go up, the proportion of the diet and budget dedicated to micronutrient-rich foods goes down. ${ }^{5}$ The World Food Programme found evidence of reductions in both quantity and quality of food consumption following the food price crisis in 2008 (Brinkman et al. 2010). Others have discussed how the poor protect their consumption in the face of food price increases, including consuming cheaper, lower-quality foods, and reducing intake overall, and reducing expenditures on non-foods (Ruel et al. 2010; Brinkman et al. 2010; Meerman and Aphane 2012; Bouis et al. 2011; von Braun et al. 2008). The poor in low-income countries spend $50-80 \%$ of their income on food (Brinkman et al. 2010), so a change in staple prices strongly affects poor consumers' real income. The effect of income on diet composition then depends on several factors including the food environment, as discussed earlier.

When non-staple prices rise, diet quality also is observed to decline. While real prices of staple grains have declined significantly, real prices of micronutrient-rich foods have increased over time (Gómez et al. 2013; Bouis et al. 2011; Graham et al. 2007). High prices of non-staples relative to declining staple grain prices over time may have served to decrease their contribution to the diet, potentially resulting in lower-quality diets despite increased quantity of dietary energy consumption (Traill et al. 2014; Pinstrup-Andersen 2013; Gómez et al. 2013; Bouis 2000).

The effects of price changes of staples and non-staples on consumption can be predicted from income elasticities of demand (the change in demand for an item based on a change in income), own-price elasticities of demand (the change in demand for an item based on a change in its price), and crossprice elasticities of demand (the change in demand for one item based on the price change of another item). Two recent papers provide a systematic review of existing own-price and crossprice elasticity data for food (Cornelsen et al. 2014; Green et al.

\footnotetext{
${ }^{5}$ Their simulation for rural Bangladesh predicts that an increase in staple prices of $100 \%$ will result in $20 \%$ decline in staple consumption and a $27 \%$ decline in non-staple consumption. (Meanwhile, a doubling of nonstaple prices will result in a $10 \%$ decline in staples and a $95 \%$ decline in non-staples.)
}

2013). Using a meta-regression model, the authors produced combined uncompensated elasticity estimates for seven food groups in low, middle, and high-income countries. A $10 \%$ increase of the price of fruits/vegetables/legumes (FVL) predicts a reduction in their consumption by $7.2 \%$ in low incomecountries $(6.5 \%$ in middle-income countries and $5.3 \%$ in high-income countries), while the same increase in cereal prices is associated with a small but significant $(0.7 \%)$ increase in FVL consumption in low-income countries (Cornelsen et al. 2014). Similarly, a $10 \%$ increase in the price of meat and dairy will reduce their consumption by $7.8 \%$ on average $(8.0 \%$ for fish), and the cross-price elasticity between cereals and meat is insignificant (Cornelsen et al. 2014; Green et al. 2013). These global estimates account for methodological differences in estimating elasticities across countries and studies. Some of the studies had negative, and some had positive cross-price elasticities between cereals and non-cereals; most were small and close to zero.

Therefore, the main conclusion, based on many different estimates using different methods is that own-price elasticities have a much larger impact on consumption of specific food groups than cross-price elasticities. ${ }^{6}$ The implication is that the strongest way to increase consumption of nutrient-rich nonstaples is to reduce their prices. The best reason to reduce staple grain prices is to increase real income, but not to improve dietary quality directly. This finding is echoed in findings that dietary variety is significantly associated with caloric availability from staples, but more strongly associated with caloric availability from non-staples (Hoddinott and Yohannes 2002). Furthermore, interventions that have deflated fruit and vegetable prices generally have found that consumption increases (Powell et al. 2009; Waterlander et al. 2013; Eyles et al. 2012; French 2003; An et al. 2013). Figure 2 summarizes the following relationships shown in the literature:

- Staple grain price down $\rightarrow$ more real income $\rightarrow$ increased dietary variety, animal-source food (ASF) consumption, and junk food consumption dependent on food environment

- Staple grain price down $\rightarrow$ weak effect of cross-price elasticities

- Staple grain price down $\rightarrow$ strong effect of own-price elasticities, staple consumption rises

- Non-staple price down $\rightarrow$ strong effect of own-price elasticities, non-staple consumption rises

\footnotetext{
${ }^{6}$ Bouis et al. (2011) similarly found in a simulation in Bangladesh that a doubling of non-staple prices will result in a much larger decline in nonstaple consumption (95\% decline) than a doubling of staple prices $(27 \%$ decline). The authors conclude that increasing consumption of non-staple foods is essential to meeting dietary requirements, especially of women and preschool children, and that economic growth and "investment in infrastructure and agricultural research to increase the production of non-staple foods" is needed to achieve increased consumption (p. S21).
} 
Fig. 2 Elasticities map. The circle signifies that the food environment has a strong effect on these relationships. The bold text highlights the most important relationships

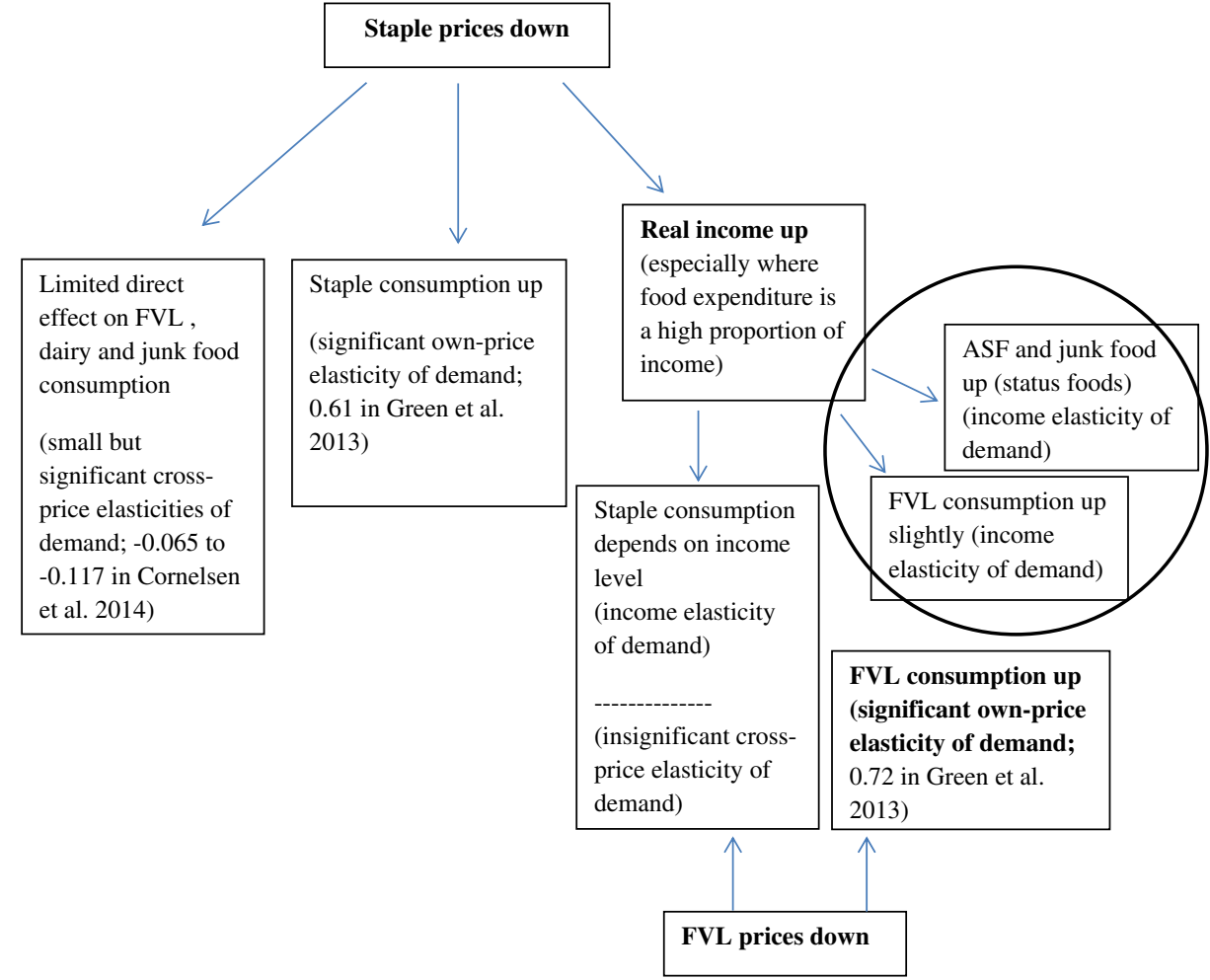

\section{Convenience}

There is not only a monetary cost of obtaining food, but also a time cost. When time is a scarce resource, convenience may be even more important than the dollar cost of food. It is well established that taste, cost, and convenience are major factors affecting food choices (Glanz et al. 1998). In the U.S., it has been discussed that somewhat in contrast to the literature demonstrating higher average cost of healthy diets compared to poor diets, it is quite possible to obtain a very healthy diet at low cost (Bittman 2011). The catch is that it will cost significantly more time to prepare (cooking vs. buying prepared food), and in some cases to obtain; in some "food deserts," getting to a supermarket can take significantly more time than a local fast food restaurant. Fast food, street food, and highlyprocessed shelf-stable food has grown quickly in urban areas because it is convenient. As people spend more time working in formal labor markets, they spend less time on food preparation. Nutritional quality of meals eaten away from home in U.S. is generally poorer than meals prepared at home (McCrory et al. 1999; French et al. 2000; Diliberti et al. 2004). Brazil has adopted dietary guidelines that emphasize home cooking because of the negative relationship between food cooked outside the home and diet quality/disease risk (Brazil Ministry of Health 2014).

One reason convenience is extremely relevant in lowincome settings, not just high-income ones, is that women's time is highly constrained all around the world. Low-income women are not only income-poor, but also time-poor (FAO 2011). Reducing women's time burdens is often discussed as a principle of improving nutrition through agriculture (FAO 2013a; Herforth and Harris 2014). Time obtaining and preparing food represents a significant time burden for women, and can vary seasonally, making convenient food particularly important in busy seasons (such as harvest time). Distance to markets can be prohibitive; in sub-Saharan Africa, some data indicate that only $20 \%$ of the rural population is able to reach a viable market in less than two hours (World Bank 2007b) - a new spin on "food deserts," a term usually applied in highincome countries. Most households do not have refrigeration or the capacity to store perishable food for long periods of time, meaning that if perishable food is not conveniently available nearby the household, it may be difficult to consume on a daily basis. If markets are far, it may be easier to grow or wildharvest food than to purchase it. Pilot work in Guatemala carried out by SPRING has shown from focus groups that convenience is one of the most important factors in mothers' decisions about food choice (Heather Danton, personal communication).

\section{Desirability}

Consumption decisions cannot only be explained by decisionmaking having to do with monetary and time costs. They also have to do with desirability of foods. Desirability could be thought of as made up of internal factors (taste) and external 
factors (status of foods, cultural norms, advertising, product placement, food quality). Here, we focus on external factors as part of the food environment. With the term "desirability" as part of the food environment, we do not refer to consumer preferences per se, but rather to external influences on preferences: that is, the factors that would change the utility function and preference ordering for certain foods.

Advertising is designed to influence food choices. Its purpose is to increase the desirability of foods. Mexico recently passed a new law limiting advertising of high-calorie food and soft drinks, because consumption is so high and has been linked to high rates of obesity. Other research has shown that less overt measures can significantly change purchasing patterns without consumers even being aware, such as product placement (Wansink 2010). It has been noted by other scholars that the public health sector could learn from the private sector on marketing skills (Curtis et al. 2007).

Quality and sensory properties of the food, including visual appeal, aroma, taste, and texture affect consumer demand and habits also. A review on measuring the food environment in Canada focuses on this aspect of desirability, calling it "food quality" (Health Canada 2013). For example, the quality of produce including its sensory aspects may not be appealing to consumers. Nutritious foods that degrade in quality can serve to deter consumers from buying these foods; lower quality produce is most often found in more disadvantaged areas of lower socio-economic status (Glanz et al. 2007; Cummins et al. 2009; Zenk et al. 2005).

Another side of desirability is the creation of knowledge and norms. Consumer education campaigns and social marketing influence attitudes about consuming certain foods. Gittelsohn et al.'s (2012) systematic review on small-store interventions to improve the food environment and dietary behaviors associated with chronic disease risk found that two of the most common strategies (in addition to increasing availability) included pointof-purchase promotions such as shelf labels and posters, and community engagement. African traditional vegetables have been marketed based on nutrition and heritage qualities, changing consumer perceptions of them as "poor man's food" (Keding et al. 2013). South Korea did a social marketing campaign of traditional food, one reason cited (next to low price and high convenience of traditional foods) for its relatively healthy dietary and nutrition pattern (Lee 2002).

Habits and norms can change over time. In the typical pattern of dietary acculturation, the diets of immigrants adapt to the new country; in the U.S., diet quality of most immigrant groups declines measurably upon acculturation (Satia-Abouta et al. 2002). Some research shows that dietary acculturation has multi-generational effects at the biological level, as tastes develop starting from young childhood and even in the womb (Gugusheff et al. 2013). So, over time, a mutually-reinforcing cycle may occur whereby dietary patterns adapt to the lack of availability of fresh foods, and demand for healthy diets declines. It may be easier to promote healthy food environments where norms already support their consumption, rather than to try to improve their desirability and shift norms after eating and nutrition transitions have already taken place.

\section{Applying the food environment concept in agriculture-nutrition evaluations}

The food environment is not present in current consideration of the agriculture-nutrition evidence base, although it likely has the largest and most pervasive effect on diets and nutrition from agriculture and food programs and policy. It has not been clear how to measure it, and a precedent has not yet been set for its inclusion in analyses of how agriculture affects nutrition. In a database of 151 current agriculture-nutrition projects, only $15 \%$ appear to be measuring any aspect of the food environment; typically availability and/or prices of specific foods (Herforth, A., \& Ballard, T. (Forthcoming). Survey of nutrition indicators in agriculture - what is being measured, what is not being measured, and what we can expect to learn). Part of this lack of attention may have to do with a lack of discussion about the food environment as an important effect modifier of income that affects diets. Many frameworks have been developed recently to illustrate the pathways from agriculture to nutrition. No fewer than 12 appear in a review of how pathways from agriculture to nutrition are currently conceptualized (Webb 2013). These existing frameworks all generally include various portrayals of income generation and use, women's empowerment, and direct consumption of own-produced food; many also include food prices for their effect on real income. Only two place the food environment between income and food consumption (Hawkes et al. 2012; Herforth and Harris 2014), in addition to a third in a conceptual framework not directly linked to the agriculture-nutrition literature (Swinburn et al. 2014).

Another factor for the lack of measurement of food environments in agriculture-nutrition literature is that indicators of the food environment are not well-established for international monitoring or use in projects. A significant body of literature exists on measuring the food environment, but it is almost exclusively in the context of high-income countries. At the same time, the food market environment has been partially measured by the agriculture sector for decades globally, through food price data (e.g. data tracked by WFP VAM and FAO). These measures, however, focus on basic staple grains or aggregate food baskets, without attention to each food group needed for a diverse, nutritious diet.

Agriculture-nutrition research would benefit from measuring food environments for three reasons. First, it would help to predict or understand the likely effect of additional income on diets. Second, for those programs or larger-scale investments that aim to reduce food prices and increase access to diverse, nutritious food, it would help to monitor/ 
evaluate their impact. Third, measuring food environments would be helpful to design better nutrition-sensitive programs to fill supply and demand gaps based on an understanding of the existing food environment. The following section reviews the current range of approaches on food environment measurement, so that existing tools may be drawn upon for application in international agriculture and nutrition. These are summarized in Table 1.

\section{Existing measures of the food environment}

A range of food environment measurements have been developed in the past few decades due to the increased interest in the complex factors that influence dietary behavior and dietrelated chronic disease. Researchers, practitioners, governments, industry, community organizations, and other institutions, mostly in the U.S. and Europe, have been active in the development of these measures. There are over 500 food environment measurements that focus on different features of the food environment through varied approaches (National Cancer Institute 2014). Most often, measures involve geographic aspects of the built food environment coupled with characterizing the presence of specific healthy and unhealthy foods. A systematic review of food environment measures from 1990 to 2007 showed that geographic analysis involving geospatial data, such as from GIS and proximity measurements of food outlets, was the most frequently used type of measure of the 137 articles found and reviewed on studies using food environment measures (McKinnon et al. 2009). These measures are proxies for the availability, affordability, convenience, and desirability of certain kinds of food.

Availability and accessibility are among the most frequently studied feature of the food environment and generally involve geographic parameters of proximity, density, and variety of food outlets at the ZIP-code and neighborhood levels. Food availability measures may quantify and characterize the actual foods available in an area and the amount of shelf-space dedicated to these items. Output from such availability measures often involves categorizing food environments as healthy or unhealthy on the basis of the food outlets and specific foods available. Gustafson et al. (2013) reported that food venue choice such as shopping at farmers' markets or specialty grocery stores resulted in higher chances of consuming fruits and vegetables. The authors also reported that the high availability of healthy food within a store results in lower chances of individuals consuming sugar-sweetened beverages. Increased number and density of supermarkets in a neighborhood is associated with lower BMI and waist circumference among diabetic youth in the U.S. (Lamichhane et al. 2013).

Affordability measurements consider the cost of foods within a defined area in either absolute, relative, or comparative terms. They have traditionally taken into account the cost of food relative to an individual's or household's purchasing power and aggregate food costs to an area level within a defined geographic area (Health Canada 2013). However, only recently have researchers incorporated local price data collection; previously, researchers drew on price tracking at the national level from government and commercial sources (Glanz 2009).

Convenience can be measured as the proximity of food outlets to homes and amounts and different types of food stores and restaurants in an area (density and variety). The concept of food deserts measures proximity to outlets with healthy foods such as grocery stores, while the concept of food swamps measure proximity to unhealthy foods such as fast food restaurants (Health Canada 2013). In addition, convenience can be measured in terms of preparation time of various kinds of foods; we are not aware of any metrics of food preparation time within the food environment literature.

Desirability measurements evaluate food quality and are among the least studied feature of the food environment (Cummins et al. 2009) yet are of great importance because overall quality of nutritious foods influences purchasing. Measures of desirability are often subjective on the basis of the perceiver as raters implementing the specific measure can disagree about the desirability of the food, such as the degree of bruising on fruits and vegetables, and willingness to purchase produce of a specific quality at a specific price. Store type can be a proxy for produce quality given the finding that grocery stores offer more fresh produce compared to convenience stores (Glanz et al. 2007). Informational aspects of the food environment affect desirability, and include media and advertising operating at various scales. Food environments may further be classified as social environments that take into account the interrelationships between individuals such as social networks as well as demographic factors such as income and age.

Despite the emerging efforts to measure the food environment at the community level and the increased recognition of the importance of the food environment in influencing dietary quality and chronic disease, the science of measuring and evaluating the food environment is in its early stages (Lytle 2009), particularly in regard to international food environments. The choice of which food environment measure to use for a specific situation should be guided by the purpose of the assessment, user needs for details and accuracy and resources and expertise available (Ohri-Vachaspati and Leviton 2010).

For relevance to agriculture interventions, particularly in rural low-income settings, different emphasis is likely needed from that of the food environment measures most commonly used to date in high-income and urban settings. Agriculturenutrition interventions typically have no influence over physical food markets or restaurants, but often can influence availability and affordability of various foods. Some agriculture 


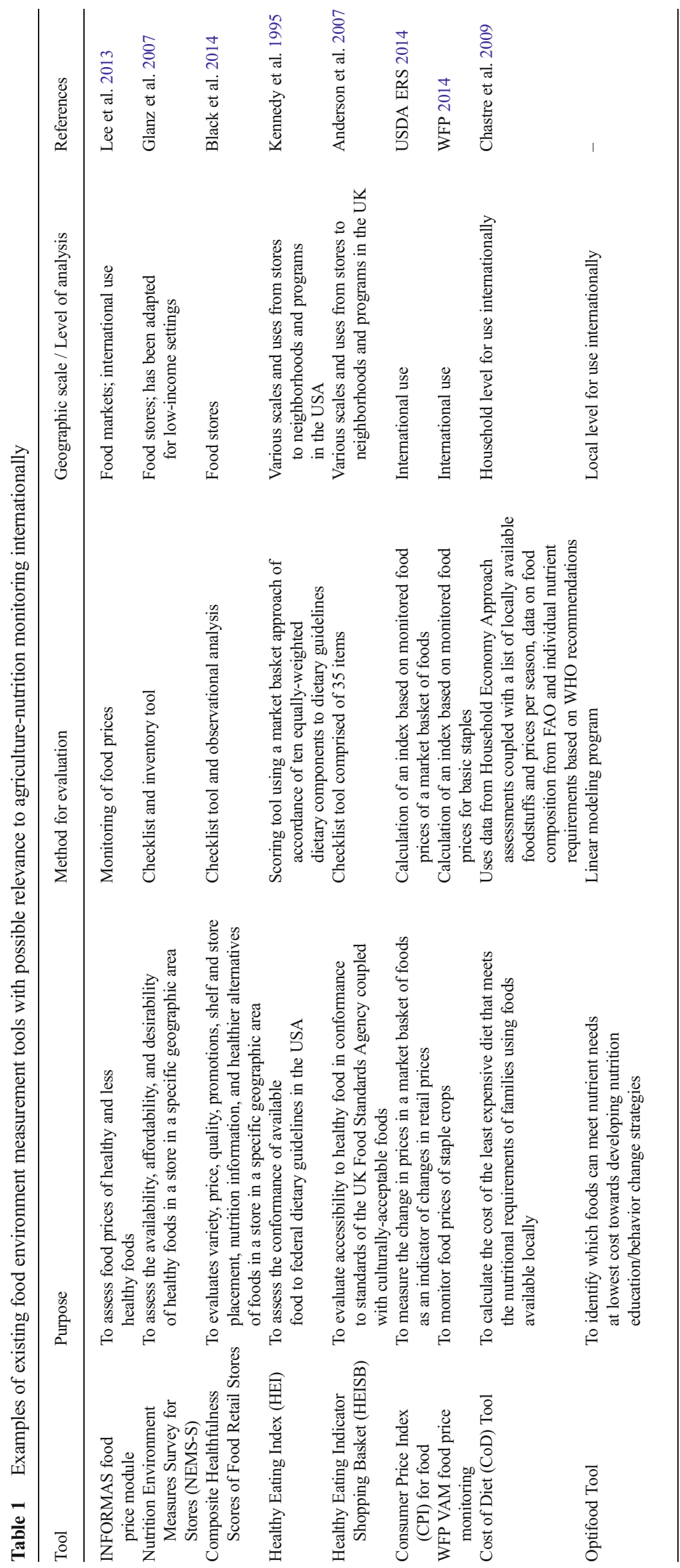


interventions may influence convenience and desirability, depending on post-harvest inputs/activities such as packaging, storage, and marketing. We next summarize specific tools identified from the food environment literature that may be relevant for use in agriculture-nutrition intervention design or monitoring and evaluation.

\section{INFORMAS food price module}

The International Network on Food and Obesity/Noncommunicable disease Research, Monitoring and Action Support (INFORMAS) is a global network of public-interest organizations and researchers that aims to monitor, benchmark and support public and private sector actions to create healthy food environments and reduce obesity, NCDs and their related inequalities (Swinburn et al. 2013). This network is developing a series of metrics to reflect healthy food environments. One, which is under development, is of food prices (Lee et al. 2013). The authors of this tool conducted a review of food environment metrics and concluded that a new framework needs to be developed for monitoring food prices; they propose one based on "healthy" and "less healthy" foods. While useful from a public health perspective, the distinction between "healthy" and "less healthy" has less resonance for agriculture, which would monitor specific foods or food groups (e.g., staple crops).

\section{Nutrition environment measures survey for stores (NEMS-S)}

The Nutrition Environment Measures Survey for Stores (NEMS-S) developed by Glanz et al. (2007) is among the food environment measurements most widely used by researchers and advocates in the United States that implements checklist and inventory tools to assess the built food environment of food stores. The NEMS-S checklist is based on the availability and relative costs (affordability) of indicator food items from various food categories. The selected food items are those identified as the most widely consumed and available foods in the United States, including both healthy and unhealthy options. NEMS-S has been tested for inter-rater reliability and test-retest reliability in neighborhoods of various socioeconomic status nationally (Glanz et al. 2007). In addition, all researchers using NEMS-S are required to complete a free online training for using this tool in order to enhance comparability of this survey between studies. Researchers have variably adapted NEMS-S for context specificity in various neighborhoods and countries such as the Revised Nutrition Environment Measures Survey (R-NEMS) designed specifically for neighborhoods of low socio-economic status (Andreyeva et al. 2008) and Kanter et al.'s (2014) modified NEMS-S for food environments in Guatemala in the form of a mobile phone application. This could be explored for further use in other low-income and rural settings.

\section{Composite healthfulness scores of food retail stores}

Healthfulness scores of food retail stores build on the parameters of NEMS-S to assess the availability of healthy foods and less healthy foods. Specifically, the healthfulness scores incorporate parameters of variety, price, quality, promotions, shelf placement, store placement, nutrition information, and healthier alternatives for each of the healthy and unhealthy foods included (Black et al. 2014).

\section{Healthy eating index (HEI)}

This tool was originally developed by the USDA for individual diets based on the Dietary Guidelines for Americans (Kennedy et al. 1995). It can be broadened beyond individual diets to examine the quality of foods available in a given food supply (Reedy et al. 2010; Krebs-Smith et al. 2010). The HEI is based on a score from 0 to 100 of ten equallyweighted dietary components with a higher score indicating that the food availability is closer to the recommended amounts. While useful for public health, its inclusion of nutrients (e.g., saturated fats) in addition to food groups may make this metric somewhat less applicable for monitoring availability of agriculturally produced foods.

\section{Healthy eating indicator shopping basket (HEISB)}

The HEISB is a tool to evaluate the accessibility of healthy food in conformance to standards of the UK Food Standards Agency coupled with culturally-acceptable foods. The tool is comprised of 35 items including 17 from fruit and vegetables, nine from bread/cereal/potatoes, five from fish and meats, three from dairy, and one from fatty and sugary foods. The HEISB provides a basis for examining availability of healthy foods in cross-sectional and longitudinal studies in the UK (Anderson et al. 2007). A tool like this, using sentinel foods, could potentially be used to assess markets in low-income settings within zones of influence of agricultural interventions.

\section{Consumer price index (CPI) for food}

A Consumer Price Index (CPI) for food measures the change in a market basket of foods. In the U.S., it is a widely used indicator of changes in retail prices, a monthly measurement of prices surveyed by the Bureau of Labor Statistics (USDA ERS 2014). It includes food consumed away from home as a single category, and food consumed at home in categories of meat, eggs, dairy, fats and oils, fruits and vegetables, sugar and sweets, cereals, beverages, 
and other foods. The methods used to calculate these food prices can be used at national and local levels.

\section{WFP VAM food price monitoring}

Closely related to the CPI, the World Food Programme (2014) hosts a "Food and Commodity Prices Data Store" as part of its Vulnerability Analysis and Mapping (VAM). It collects data monthly, and calculates a CPI quarterly for basic staples. The price monitoring is only done for staple grains, but the methodology could be adapted to many food groups. In many countries, agricultural extension has some role in gathering market price data for food. Depending on capacity and comprehensiveness, these data could be leveraged for monitoring availability and affordability of diverse diets.

\section{Subjective measures of food availability}

Perceived availability predicts consumption; greater perceived access to fruits and vegetables was significantly associated with higher increases in fruit and vegetable consumption (Caldwell et al. 2009). While some studies have shown that self-reported perceptions of food access correlate well with objective assessments of the local food environment (Freedman and Bell 2009), others conclude that subjective measures do not line up to objective food environment measures (Moore et al. 2009; Williams et al. 2011; Winkler et al. 2006). Subjective measurements are thus important to take into consideration when evaluating how people interact with their environments to purchase and consume food (Cummins 2007). Interviews and questionnaires present a commonly utilized approach with more subjective data, including consumer perceptions of the food environment such as the Perceived Availability of Healthy Food Questions (Moore et al. 2008).

\section{Cost of diet tool}

The Cost of Diet tool was developed by Save the Children, UK for an international nutrition context to calculate the cost of the least expensive diet that meets the nutritional requirements of families using foods available locally (Chastre et al. 2009). The CoD uses data from Household Economy Approach assessments (Save the Children 2014), coupled with a list of locally available foodstuffs and prices per season, data on food composition from the Food and Agriculture Organization (FAO), and individual nutrient requirements based on World Health Organization (WHO) recommendations. Output from the $\mathrm{CoD}$ can identify foods that are the least or most expensive sources of energy and nutrients towards designing interventions targeted at improving dietary quality. A possible application of this tool for agriculture would be to signal which nutrient-dense and desirable foods are unaffordable, in order to target their production. However, this tool is time-consuming to implement and may not be feasible in most program monitoring and evaluation systems.

\section{Optifood tool}

Optifood is a computer software program that was developed by WHO et al. for an international nutrition context to improve dietary quality through the lowest cost using locally available foods. Findings from this program can identify nutrient gaps and suggests food combinations that the local diet can fill towards developing strategies for nutrition education and behavioral change interventions. For example, Optifood analysis in communities that are part of the USAID-funded Feed the Future Initiative in Guatemala identified a combination of locally available foods and a fortified cereal along with mother's breast milk to satisfy most children's nutrient needs. The main purpose is to identify which foods can meet nutrient needs at lowest cost, in order to come up with nutrition education/behavior change strategies; not to monitor affordability of diverse foods. The foods identified by this tool could potentially be targeted for household-level or communitylevel production in interventions.

\section{Next steps}

We find that few existing measures are directly relevant for application to agricultural settings internationally (many having been developed in high-income settings), or for understanding the impact of agricultural interventions on consumers. There are some tools that could be used or modified to assess availability and affordability of nutritious foods. While convenience and desirability are important, they are complex to measure, and limited methodologies currently exist to build upon. The primary need is the development of measures of availability and affordability of the components of a diverse, nutritious diet as these are not only most feasible to measure, they are also crucial factors for determining food security. Availability and affordability within a specified geographic range are the external (non-intra-household) factors that determine food "access."

Key research questions include: (1) How to develop reliable, feasible, objective and/or subjective measures of availability and affordability of diverse, nutritious diets; (2) Under which circumstances should they be part of agriculturenutrition evaluations? Such metrics might be more applicable in national monitoring frameworks, from which any given program could draw. (3) How to measure all aspects (including convenience and desirability), and all parts of the food environment (farm and natural environments, in addition to market environment). Should there be a dashboard of several measures, or one composite measure? 
A notable need for a food environment measure useful for agriculture-nutrition monitoring is an objective measure of prices of various food groups. Specifically, there is a need to develop, standardize and mainstream methods for aggregating data and deriving a price that represents the whole food group. While there is not a clear established methodology to achieve this in a way that is easily collected, analyzed and communicated, several of the existing tools listed above provide valuable insights toward the development of a feasible, valid metric of diverse food access. For example, the methods WFP uses for weekly monitoring of food staple prices could be adapted to other non-staples. A CPI for various food groups might also be tracked, given adequate capacity for the needed data collection and analysis. Additional methodological insights may be gained from the experiences of developing the Cost of Diet and Optifood tools, which may be useful for designing household-level interventions.

Another measure that is worthy of developing is a subjective measure of availability and affordability of diverse nutritious foods. Previous studies have found that perceptions of the food environment are more strongly correlated to food-related behaviors and diet quality than objective food environment measures (Giskes et al. 2007; Zenk et al. 2005; Inglis et al. 2008). Existing subjective measures of availability and affordability could be further explored to develop such a methodology.

Ultimately, it would be useful to capture all aspects of the food environment, including convenience and desirability. Measures such as time or distance to markets, or the kinds of markets easiest to access, could be developed based on many of the U.S. metrics of restaurants and grocery stores. Preparation time of foods could be an aspect to add to metrics. The INFORMAS group is developing metrics of food retail and promotion that could capture aspects of desirability (Swinburn et al. 2013); attitude scales about certain foods could be another angle to capture desirability in terms of norms. Measures such as the NEMS-S, which have already been tested in a low-income country, could be useful to examine for capturing the food environment holistically.

\section{Conclusion}

This paper explores the potential of measuring the food environment within agriculture-nutrition interventions. We emphasized that the effect of income on consumption is always modified by the food environment. The food environment can be defined as availability, affordability, convenience, and desirability of various foods. This is similar to other definitions, but adds convenience, and uses the broader term "desirability" which encompasses but is more than "quality." These four factors influence consumption. Policy and sociocultural aspects affect these four aspects of the food environment. Availability and affordability within a specified geographic range are the external (non-intra-household) factors that determine food access.

The food environment of markets is not present in current consideration of the agriculture-nutrition evidence base, although it likely has a large and pervasive effect on diets and nutrition from agriculture programs and policy. All commercial agriculture affects the food environment at the same time as it affects income (often, it also affects control of income within the household). The interaction between income and the food environment explain why household income has a variable - and sometimes seemingly unpredictable, or less than expected - impact on nutrition. Income can have a strong positive influence where the food environment enables its use on healthy diets. Increased income may worsen nutrition in some ways (such as by increasing obesity and chronic disease) when food environments facilitate spending toward unhealthy diets.

The development of food environment metrics could benefit agriculture-nutrition interventions in several ways. They could track the impact of these interventions on food environments and could be used to increase understanding of how income is likely to affect diets. In addition, food environment measures could be used to assess food gaps to better inform the design of agriculture-nutrition programs. While there are many ways the food environment has been measured, it has not been clear how to measure food environments in agriculture-nutrition interventions and a precedent has not yet been set for its inclusion in this context. Some existing measures are relevant to apply internationally in rural areas, but none is immediately feasible and scalable without streamlining and mainstreaming a methodology. Further analysis and research is needed. The primary need is a measure of affordability of the components of a diverse diet. This could be an objective or a subjective measure. Other non-market parts of the food environment also need to be understood, such as on-farm and natural/wild food environments.

Ultimately, metrics are needed to inform strategies for improving food environments. The most effective strategies will vary by stage of the nutrition transition. In places where norms and habits support traditional food culture, reducing cost of a healthy traditional diet may be a relatively effective way to improve diets (i.e., where supply of nutritious foods does not meet demand). In places where diets have transitioned to high intakes of ultra-processed foods, more emphasis on convenience and desirability may be needed.

Acknowledgments AH's work on this review was supported by SPRI NG. SA's work on this review was supported by NIGMS Montana IDeA Network for Biomedical Research Excellence (NIH NIGMS P20GM103474). We would like to thank Daniel Schultz, Lacy Stevens, Miranda Margetts, Alyssa Klein, and Samantha Clark for their support in identifying some of the literature reviewed in this paper. 
Open Access This article is distributed under the terms of the Creative Commons Attribution 4.0 International License (http:// creativecommons.org/licenses/by/4.0/), which permits unrestricted use, distribution, and reproduction in any medium, provided you give appropriate credit to the original author(s) and the source, provide a link to the Creative Commons license, and indicate if changes were made.

\section{References}

Alexandratos, N., \& Bruinsma, J. (2012). World agriculture towards 2030/2050: The 2012 revision. ESA Working Paper No. 12-03. Rome: Food and Agriculture Organization of the United Nations.

An, R., Patel, D., Segal, D., \& Sturm, R. (2013). Eating better for less: A national discount program for healthy food purchases in South Africa. Am J Health Behavior, 37(1), 56-61.

Anderson, A., Dewar, J., Marshall, D., Cummins, S., Taylor, M., Dawson, J., et al. (2007). The development of a healthy eating indicator shopping basket tool (HEISB) for use in food access studies-identification of key food items. Public Health Nutrition, 10(12), 1440-1447.

Andreyeva, T., Blumenthal, D. M., Schwartz, M. B., Long, M. W., \& Brownell, K. D. (2008). Availability and prices of foods across stores and neighborhoods: the case of New Haven, Connecticut. Health Affairs, 27(5), 1381-1388.

Barquera, S., Hernandez-Barrera, L., Tolentino, M. L., Espinosa, J., Ng, S. W., Rivera, J. A., \& Popkin, B. M. (2008). Energy intake from beverages is increasing among Mexican adolescents and adults. Journal of Nutrition, 138(12), 2454-2461.

Behrman, J., \& Deolalikar, A. (1989). Is variety the spice of life? Implications for calorie intake. Review of Economics and Statistics, 71(4), 666-672.

Bittman, M. (2011). Is junk food really cheaper? The New York Times, http://www.nytimes.com/2011/09/25/opinion/sunday/is-junk-foodreally-cheaper.html. Accessed 29 Mar 2012.

Black, C., Ntani, G., Inskip, H., Cooper, C., Cummins, S., Moon, G., et al. (2014). Measuring the healthfulness of food retail stores: variations by store type and neighbourhood deprivation. International Journal of Behavioral Nutrition and Physical Activity, 11, 69.

Bouis, H. E. (2000). Special issue on improving nutrition through agriculture. Food and Nutrition Bulletin, 21(4), 356-360.

Bouis, H., Eozenou, P., \& Rahman, A. (2011). Food prices, household income, and resource allocation: socioeconomic perspectives on their effects on dietary quality and nutritional status. Food and Nutrition Bulletin, 32(1), S14-S23.

Brazil Ministry of Health. (2014). Guia alimentar para a populacao Brasileira.

Brinkman, H., de Pee, S., Sanogo, I., Subran, L., \& Bloem, M. W. (2010). High food prices and the global financial crisis have reduced access to nutritious food and worsened nutritional status and health. Journal of Nutrition, 140, 153S-161S.

Brownell, K. D., Kersh, R., Ludwig, D. S., Post, R. C., Puhl, R. M., Schwartz, M. B., et al. (2010). Personal responsibility and obesity: A constructive approach to a controversial issue. Health Affairs, 29(3), 378-386.

Caldwell, E. M., Miller Kobayashi, M., DuBow, W. M., \& Wytinck, S. M. (2009). Perceived access to fruits and vegetables associated with increased consumption. Public Health Nutrition, 12(10), 1743-1750.

CGIAR. (2014). Big facts: food security. http://ccafs.cgiar.org/ bigfacts $2014 /$ \#theme=food-security\&subtheme=food-demand. Accessed 15 Oct 2014

Chastre, C., Duffield, A., Kindness, H., LeJeune, S., \& Taylor, A. (2009). The minimum cost of a healthy diet: findings from piloting a new methodology in four study locations. Save the Children Report.
Cornelsen, L., Green, R., Turner, R., Dangour, A., Shankar, B., Mazzocchi, M., et al. (2014). What happens to patterns of food consumption when food prices change? Evidence from a systematic review and meta-analysis of food price elasticities globally. Health Economics. doi:10.1002/hec.3107.

Cummins, S. (2007). Neighbourhood food environment and diet - time for improved conceptual models? Preventive Medicine, 44(3), 196-197.

Cummins, S., Smith, D. M., Taylor, M., Dawson, J., Marshall, D., Sparks, L., \& Anderson, A. S. (2009). Variations in fresh fruit and vegetable quality by store type, urban-rural setting and neighbourhood deprivation in Scotland. Public Health Nutrition, 12(11), 2044-2050.

Curtis, V. A., Garbrah-Aldoo, N., \& Scott, B. (2007). Masters of Marketing: Bringing private sector skills to public health partnerships. American Journal of Public Health, 97(4), 634-641.

Diliberti, N., Bordi, P. L., Conklin, M. T., Roe, L. S., \& Rolls, B. J. (2004). Increased portion size leads to increased energy intake in a restaurant meal. Obesity Research, 12, 562-568.

Drewnowski, A., \& Darmon, N. (2005a). Food choices and diet costs: an economic analysis. Journal Nutrition, 135, 900-904.

Drewnowski, A., \& Darmon, N. (2005b). The economics of obesity: dietary energy density and energy cost. American Journal of Clinical Nutrition, 82(suppl), 265S-273S.

Drewnowski, A., \& Popkin, B. M. (1997). The nutrition transition: New trends in the global diet. Nutrition Reviews, 55(2), 31-43.

Drewnowski, A., Moudon, A. V., Jiao, J., Aggarwal, A., Charreire, H., \& Chaix, B. (2013). Food environment and socioeconomic status influence obesity rates in Seattle and in Paris. International Journal of Obesity. doi:10.1038/ijo.2013.97.

$\mathrm{Du}, \mathrm{L}$. (2014). Leveraging agriculture for nutritional impact through the Feed the Future Initiative: A landscape analysis of activities across 19 Focus Countries. Arlington: USAID/Strengthening Partnerships, Results, and Innovations in Nutrition Globally (SPRING) Project.

Dufour, D. L., Goodman, A. H., \& Pelto, G. H. (2012). Biocultural Perspectives on Food and Nutrition (2nd ed.). USA: Oxford University Press.

Eyles, H., Ni Mhurcu, C., Nghiem, N., \& Blakely, T. (2012). Food pricing strategies, population diets and non-communicable disease: A systematic review of simulation studies. PLOS Medicine, 9, 1-22.

FAO. (2013a). Synthesis of guiding principles on agriculture programming for nutrition. Rome: FAO.

FAO. (2013b). The state of food and agriculture: food systems for better nutrition. Rome: FAO.

Foley, J. (2014). Feeding 9 billion: A five-step plan to feed the world. National Geographic Magazine. http://www.nationalgeographic. com/foodfeatures/feeding-9-billion/. Accessed 15 Oct 2014.

Food and Agriculture Organization of the United Nations (FAO). (2011). The state of food and agriculture 2010-2011: women in agriculture: closing the gender gap for development. Rome: FAO.

Freedman, D. A., \& Bell, B. A. (2009). Access to healthful foods among an urban food insecure population: perceptions versus reality. Journal of Urban Health, 86(6), 825-838.

French, S. A. (2003). Pricing effects on food choices. Journal of Nutrition, 133, 841-843.

French, S. A., Harnack, L., \& Jeffery, R. W. (2000). Fast food restaurant use among women in the Pound of Prevention study: dietary, behavioral and demographic correlates. International Journal of Obesity and Related Metabolic Disorders, 24, 1353-1359.

Giskes, K., van Lenthe, F. J., Brug, J., Mackenbach, J. P., \& Turrell, G. (2007). Socioeconomic inequalities in food purchasing: the contribution of respondent-perceived and actual (objectively measured) price and availability of foods. Preventative Medicine, 45(1), 41-48.

Gittelsohn, J., Rowan, M., \& Gadhoke, P. (2012). Interventions in small food stores to change the food environment, improve diet, and reduce risk of chronic disease. Preventing Chronic Disease, 9, 110015 . 
Glanz, K. (2009). Measuring food environments: a historical perspective. American Journal of Preventative Medicine, 36(4S).

Glanz, K., Basil, M., Maibach, E., Goldberg, J., \& Snyder, D. (1998). Why Americans eat what they do: taste, nutrition, cost, convenience, and weight control concerns as influences on food consumption. Journal of American Dietetics Association, 98, 1118-1126.

Glanz, K., Sallis, J. F., Saelens, B. E., \& Frank, L. D. (2005). Healthy nutrition environments: concepts and measures. American Journal of Health Promotion, 19(5), 330-333.

Glanz, K., Sallis, J. F., Saelens, B. E., \& Frank, L. D. (2007). Nutrition environment measures survey in stores (NEMS-S): development and evaluation. American Journal of Preventative Medicine, 32(4), 282-289.

Gómez, M. I., et al. (2013). Post-green revolution food systems and the triple burden of malnutrition. Food Policy. doi:10.1016/j.foodpol. 2013.06.009

Graham, R., Welch, R., Saunders, D., Ortiz-Monasterio, I., Bouis, H., \& Bonierbale, M. (2007). Nutritious subsistence food systems. Advances in Agronomy, 92, 1-74.

Green, R., Cornelsen, L., Dangour, A. D., Turner, R., Shankar, B., Mazzocchi, M., \& Smith, R. D. (2013). The effect of rising food prices on food consumption: systematic review with meta-regression. $B M J, 346, \mathrm{f} 3703$.

Guenther, P. M., Reedy, J., \& Krebs-Smith, S. M. (2008). Development of the healthy eating index-2005. Journal of the American Dietetic Association, 108(11), 1896-1901.

Gugusheff, J. R., Ong, Z. Y., \& Muhlhausler, B. S. (2013). A maternal "junk-food" diet reduces sensitivity to the opioid antagonist naloxone in offspring postweaning. The FASEB Journal, 27(3), 1275-1278.

Gustafson, A., Christian, J. W., Lewis, S., Moore, K., \& Jilcott, S. (2013). Food venue choice, consumer food environment, but not food venue availability within daily travel patterns are associated with dietary intake among adults, Lexington Kentucky 2011. Nutrition Journal, $12,17$.

Hawkes, C., Turner, R., \& Waage, J. (2012). Current and Planned Research on Agriculture for Improved Nutrition: A Mapping and a Gap Analysis. Report for the Department for International Development (DFID). London: Leverhulme Centre for Integrative Research on Agriculture and Health.

Health Canada. (2013). Measuring the food environment in Canada. www.hc-sc.gc.ca/fn-an/nutrition/pol/index-eng.php. Accessed 15 Oct 2014

Herforth, A. (2015). Access to adequate nutritious food: new indicators to track progress and inform action. In D. Sahn (Ed.), New directions in the fight against hunger and malnutrition. New York: Oxford University Press.

Herforth, A., \& Harris, J. (2014). Understanding and applying primary pathways and principles. Brief\#1. Improving nutrition through agriculture technical brief series. Arlington: USAID/Strengthening Partnerships, Results, and Innovations in Nutrition Globally (SPRING) Project.

Hoddinott, J., \& Yohannes, Y. (2002). Dietary Diversity as a food security indicator. IFPRI FCND Discussion Paper No. 136. Washington, D.C.: International Food Policy Research Institute.

Inglis, V., Ball, K., \& Crawford, D. (2008). Socioeconomic variations in women's diets: what is the role of perceptions of the local food environment? Journal of Epidemiology and Community Health, 62(4), 376-376.

Institute for Health Metrics and Evaluation (IHME). (2013). Global Burden of Disease Interactive Tool. http://www. healthmetricsandevaluation.org/tools/data-visualizations. Accessed 15 Oct 2014.

International Diabetes Federation. (2013). IDF Diabetes Atlas (6th ed.). Brussels: International Diabetes Federation.

Kanter, R., Alvey, J., \& Fuentes, D. (2014). Creation of a mobile-phone application for assessing supermarket offerings for a Guatemalan- based exploration of the Nutrient Environment Measurement Survey-Stores. The FASEB Journal, 28(1), 255.1.

Keats, S., \& Wiggins, S. (2014). Future diets: implications for agriculture and food prices. London: Overseas Development Institute.

Keding, G. B., Schneider, K., \& Jordan, I. (2013). Production and processing of foods as core aspects of nutrition-sensitive agriculture and sustainable diets. Food Security. doi:10.1007/s12571-013-0312-6.

Kennedy, E. T., Ohls, J., Carlson, S., \& Fleming, K. (1995). The healthy eating index: design and applications. Journal of the American Dietetic Association, 95(10), 1103-1108.

Khoury, C., Bjorkman, A. D., Dempewolfe, H., Ramirez-Villegas, J., Guarinof, L., Jarvisa, A., et al. (2014). Increasing homogeneity in global food supplies and the implications for food security. Proceedings of the National Academy of Sciences, 111(11), 4001-4006.

Krebs-Smith, S., Reedy, J., \& Bosire, C. (2010). Healthfulness of the U.S. food supply: Little improvement despite decades of dietary guidance. American Journal of Preventative Medicine, 38(5), 472-477.

Lamichhane, A. P., Warren, J., Puett, R., Porter, D. E., Bottai, M., MayerDavis, E. J., \& Liese, A. D. (2013). Spatial patterning of supermarkets and fast food outlets with respect to neighborhood characteristics. Health Place, 23, 157-164.

Larson, N., \& Story, M. (2009). A review of environmental influences on food choices. Annals of Behavioral Medicine, 38(Suppl 1), S56-S73.

Lee, M. (2002). The unique aspect of the nutrition transition in South Korea: the retention of healthful elements in their traditional diet. Public Health Nutrition, 5(1A), 197-203.

Lee, A., Mhurchu, C. N., Sacks, G., Swinburn, B., Snowdon, W., Vandevijvere, S., et al. (2013). Monitoring the price and affordability of foods and diets globally. Obesity Reviews, 14(Suppl 1), 82-95.

Lytle, L. A. (2009). Measuring the food environment: state of the science. American Journal of Preventative Medicine, 36(4 Suppl), S134-S144.

McCrory, M. A., Fuss, P. J., Hays, N. P., Vinken, A. G., Greenberg, A. S., \& Roberts, S. B. (1999). Overeating in America: association between restaurant food consumption and body fatness in healthy adult men and women ages 19 to 80. Obesity Research, 7, 564-571.

McKinnon, R. A., Reedy, J., Morrissette, M. A., Lytle, L. A., \& Yaroch, A. L. (2009). Measures of the food environment: a compilation of the literature, 1990-2007. American Journal of Preventative Medicine, 36(4 Suppl), S124-S133.

Meerman, J., \& Aphane, J. (2012). Impact of high food prices on nutrition. Rome: FAO.

Monteiro, C. (2009). The decline in child malnutrition in Brazil. Cad Saúde Pública, Rio de Janeiro, 25(5), 950-951.

Monteiro, C., Conde, W. L., \& Popkin, B. M. (2007). Income-specific trends in obesity in Brazil: 1975-2003. American Journal of Public Health, 97, 1808-1812.

Monteiro, C., Gomes, F., \& Cannon, G. (2010). The snack attack. American Journal of Public Health, 100(6), 975-981.

Monteiro, C., Levya, B., Claroa, R., de Castro, R. R. I., \& Cannona, G. (2011). Increasing consumption of ultra-processed foods and likely impact on human health: evidence from Brazil. Public Health Nutrition, 14(1), 5-13.

Moodie, R., Stuckler, D., Monteiro, C., Sheron, N., Neal, B., \& Thamarangsi, T. (2013). Profits and pandemics: prevention of harmful effects of tobacco, alcohol, and ultraprocessed food and drink industries. The Lancet, 381, 670-679.

Moore, L. V., Roux, A. V. D., Nettleton, J. A., \& Jacobs, D. R. (2008). Associations of the local food environment with diet quality - a comparison of assessments based on surveys and geographic information systems. American Journal of Epidemiology, 167(8), 917-924.

Moore, L. V., Diez Roux, A. V., Nettleton, J. A., Jacobs, D. R., \& Franco, M. (2009). Fast food consumption, diet quality, and neighborhood exposure to fast food: the multi-ethnic study of atherosclerosis. American Journal of Epidemiology, 170(1), 29-36.

Morris, M., Hulme, C., Clarke, G. P., Edwards, K. L., \& Cade, J. E. (2014). What is the cost of a healthy diet? Using diet data from the 
UK Women's Cohort Study. Journal of Epidemiology and Community Health. doi:10.1136/jech-2014-204039.

Muhammad, A., Seale, J. L., Meade, B., \& Regmi, A. (2011). International evidence on food consumption patterns: An update using 2005 international comparison program data. USDA Economic Research Service Technical Bulletin Number 1929. Washington, D.C: USDA.

National Cancer Institute. (2014). Division of Cancer Central and Population Sciences, Applied Research. Measures of the food environment. Bethesda: National Cancer Institute. http:// appliedresearch.cancer.gov/mfe/. Accessed 15 Oct 2014.

Ohri-Vachaspati, P., \& Leviton, L. C. (2010). Measuring food environments: a guide to available instruments. American Journal of Health Promotion, 24(6), 410-426.

Pingali, P. (2006). Westernization of Asian diets and the transformation of food systems: Implications for research and policy. Food Policy, 32, 281-298.

Pinstrup-Andersen, P. (2013). Nutrition-sensitive food systems: from rhetoric to action. The Lancet, 382(9890), 375-376.

Popkin, B. M., \& Du, S. (2003). Dynamics of the nutrition transition toward the animal foods sector in China and its implications: a worried perspective. Journal of Nutrition, 133, 3898S-3906S.

Popkin, B. M., Duffey, K., \& Gordon-Larsen, P. (2005). Environmental influences on food choice, physical activity and energy balance. Physiology \& Behavior, 86, 603-613.

Popkin, B. M., Adair, L. S., \& Ng, S. W. (2012). Global nutrition transition and the pandemic of obesity in developing countries. Nutrition Reviews, 70(1), 3-21.

Powell, B., Ickowitz, A., Termote, C., Thilsted, S., Sunderland, T., Herforth, A. (2015). Strategies to improve diets with wild and cultivated biodiversity from across the landscape. Food Security.

Powell, L. M., Zhao, Z., \& Wang, Y. (2009). Food prices and fruit and vegetable consumption among young American adults. Health \& Place, 15, 1064-1070.

Rao, M., Afshin, A., Singh, G., \& Mozaffarian, D. (2013). Do healthier foods and diet patterns cost more than less healthy options? A systematic review and meta-analysis. BMJ Open. doi:10.1136/ bmjopen-2013-004277.

Reedy, J., Krebs-Smith, S., \& Bosire, C. (2010). Evaluating the food environment: application of the healthy eating index-2005. American Journal of Preventative Medicine, 38(5), 465-471.

Ruel, M., Garrett, J., Hawkes, C., \& Cohen, M. (2010). The food, fuel, and financial crises affect the urban and rural poor disproportionately: A review of the evidence. Journal of Nutrition, 140, 170S-176S.

Satia-Abouta, J., Patterson, R. E., Neuhouser, M. L., \& Elder, J. (2002). Dietary acculturation: applications to nutrition research and dietetics. Journal of the American Dietetic Association, 102, 1105-1118.

Save the Children. Household economy approach and cost of diet website. http://www.heawebsite.org/. Accessed 2 Dec 2014.

Siegel, K., Ali, M. K., Srinivasiah, A., Nugent, R. A., \& Venkat Narayan, K. M. (2014). Do we produce enough fruits and vegetables to meet global health need? PLoS One, 9(8), e104059. doi:10.1371/journal. pone. 0104059 .

Smith, L. C., Ramakrishnan, U., Ndiaye, A., Haddad, L., \& Martorell, R. (2003). The Importance of Women's Status for Child Nutrition in Developing Countries. IFPRI Research Report 131. Washington, DC: IFPRI

Story, M., Kaphingst, K. M., Robinson-O'Brien, R., \& Glanz, K. (2008). Creating healthy food and eating environments: Policy and environmental approaches. Annual Review of Public Health, 29, 253-272.

Swinburn, B. A., Sacks, G., Hall, K. D., McPherson, K., Finegood, D. T., Moodie, M. L., \& Gortmaker, S. (2011). The global obesity pandemic: shaped by global drivers and local environments. The Lancet, 378, 804-814.

Swinburn, B., Vandevijvere, S., Kraak, V., Sacks, G., Snowdon, W., Hawkes, C., et al. (2013). Monitoring and benchmarking government policies and actions to improve the healthiness of food environments: A proposed Government Healthy Food Environment Policy Index. Obesity Reviews, 14(Suppl. 1), 24-37.

Swinburn, B., Dominich, C. H., \& Vandevijvere, S. (2014). Benchmarking food environments: experts' assessments of policy gaps and priorities for the New Zealand government. Auckland: University of Auckland.

Temple, N. J., \& Steyn, N. P. (2011). The cost of a healthy diet: a South African perspective. Nutrition, 27(5), 505-508.

Traill, W. B., Mazzocchi, M., Shankar, B., \& Hallam, D. (2014). Importance of government policies and other influences in transforming global diets. Nutrition Reviews, 72(9), 591-604.

UNICEF. (2011). Gender influences on child survival, health, and nutrition: a narrative review. New York: UNICEF.

USAID. (2014). Infographic: The global state of agriculture. http://50. usaid.gov/infographic-the-global-state-of-agriculture/. Accessed 15 Oct 2014.

USDA and U.S. Department of Health and Human Services (DHHS). (2010). Dietary guidelines for Americans (7th ed.). Washington, DC: U.S. Government Printing Office.

USDA Economic Research Service. (2014). Consumer Price Index (CPI) overview. http://www.ers.usda.gov/data-products/food-priceoutlook. Accessed 15 Oct 2014.

von Braun, J., \& Kennedy, E. (Eds.). (1994). Agricultural commercialization, economic development, and nutrition. Baltimore: Johns Hopkins University Press

von Braun, J., Ahmed, A., Asenso-Okyere, K., Fan, S., Gulati, A., Hoddinott, J., et al. (2008). High food prices: the what, who, and how of proposed policy actions. Washington, DC: International Food Policy Research Institute (IPPRI).

Wansink, B. (2010). From mindless eating to mindlessly eating better. Physiology \& Behavior, 100(5), 454-463.

Waterlander, W. E., de Boer, M. R., Schuit, A. J., Seidell, J. C., \& Steenhuis, I. H. (2013). Price discounts significantly enhance fruit and vegetable purchases when combined with nutrition education: a randomized controlled supermarket trial. American Journal of Clinical Nutrition, 97, 886-895.

Webb, P. (2013). Impact pathways from agricultural research to improved nutrition and health: Literature analysis and research priorities. Rome: FAO.

Webb, P., \& Block, S. (2012.) Support for agriculture during economic transformation: impacts on poverty and undernutrition. Proceedings of the National Academy of Sciences of the United States of America, 109, 12309-12314.

Williams, L. K., Thornton, L., Ball, K., \& Crawford, D. (2011). Is the objective food environment associated with perceptions of the food environment? Public Health Nutrition, 15(2), 291-298.

Winkler, E., Turrell, G., \& Patterson, C. (2006). Does living in a disadvantaged area entail limited opportunities to purchase fresh fruit and vegetables in terms of price, availability, and variety? Findings from the Brisbane Food Study. Health Place, 12, 741-748.

World Bank. (2007a). From agriculture to nutrition: pathways, synergies, and outcomes. Washington, D.C.: World Bank.

World Bank. (2007b). World development report: agriculture for development. Washington, D.C.: World Bank.

World Bank. (2014). Learning from World Bank History: Agriculture and Food-Based Approaches to Address Malnutrition. Agricultural and Environmental Sciences Discussion Paper 10, World Bank Report No. 88740-GLB. Washington, D.C.: World Bank.

World Food Programme. (2014). Food and commodity prices data store. http://foodprices.vam.wfp.org/. Accessed 15 Oct 2014.

Zenk, S., Schulz, A. J., Israel, B. A., James, S. A., Bao, S., \& Wilson, M. L. (2005). Neighborhood racial composition, neighborhood poverty, and the spatial accessibility of supermarkets in metropolitan Detroit. American Journal of Public Health, 95(4), 660. 


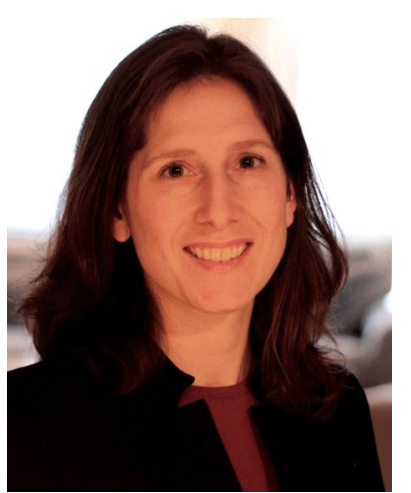

Anna Herforth is a consultant specializing in the links between nutrition, agriculture and the environment. She consults for the World Bank, the UN Food and Agriculture Organization (FAO), and USAID's SPRING Project, among others. She has worked with universities, nonprofit organizations, and the CGIAR on food and nutrition in Africa, South Asia, and Latin America. She holds a Ph.D. from Cornell University in International Nutrition, an M.S. in Food Policy from Tufts Friedman School, and a B.S. in Plant Science from Cornell University. She is a founding member of the Agriculture-Nutrition Community of Practice (Ag2Nut).

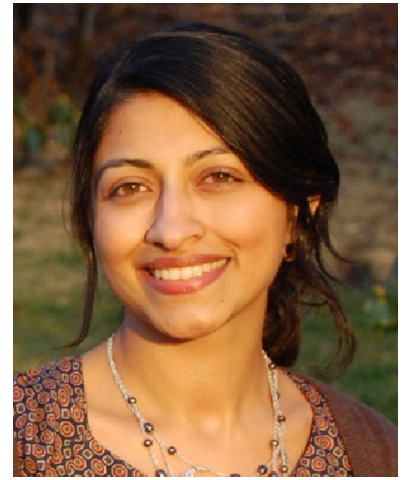

Selena Ahmed is an Assistant Professor of Sustainable Food Systems at Montana State University where she leads the Food and Health Lab. Basic, clinical and applied projects in this lab examine the socio-ecological, phytonutrient, behavioral and sensory basis of food systems. Examples of projects in this lab include: (1) impacts of agroecosystem management on biodiversity and dietary quality; (2) food environment assessment and; (3) climate effects on specialty crop quality and socio-economic responses. The ultimate goal of this work is to inform evidence-based management plans and outreach to mitigate risk in food systems towards enhanced sustainability. 